\title{
The Origin of Species as revealed by Vertebrate Palæontology. ${ }^{1}$
}

\author{
By Dr. Henry Fairfield Osborn,
}

Senior Geologist, U.S. Geological Survey; Hon. Curator Vertebrate Palæontology, American Museum of Natural History; Research Professor of Zoology, Columbia University.

I. TUST as in the inorganic world energy directs matter, not matter energy, so motion or function invariably precedes form; change of motion or function precedes change of form. ${ }^{3}$ A static condition of form, in either the trunk, the limbs, the vertebræ, or the teeth, implies a static condition of habit, of habitat, or of function; consequently, a new habit (ontogeny), in either the unchanged or changing environment, gives rise to a new movement or function and results in change of form in the organ most directly affected. Each particular organ and each part of an organ may manifest a dependent or independent change of function and consequent change of form ; thus a series of organs or of closely related or similar parts of the same organ may manifest either harmonic or disharmonic change. This principle, first observed by Aristotle, more or less developed by Lamarck, and more specifically by Cope, has been confirmed by such observations as those of Arbuthnot Lane.

II. The principle of compensation on economy of growth, first formulated by Aristotle and later more clearly by Geoffrey St. Hilaire (loi de balancement des organes), whereby the increased motion or function of one organ is compensated for by diminished motion or function of another organ, is a bio-mechanical principle thoroughly established in vertebrate palæontology; not only adjacent or related organs, but organs widely separated functionally and anatomically rigidly obey this economic law, which receives its most substantial demonstration in palæontologic series. Its corollary is development and perfection through use and degeneration through disuse.

III. The principle of continuity, in which evolution is like growth, is one which could be discovered and observed only in palæontology, where large numbers of successive lines of descent of organisms can be observed. To our knowledge, this principle was first observed by the invertebrate palæontologist Waagen in I 869, who observed continuous change whereby a minute and inconspicuous organ gradually in geologic succession becomes so conspicuous as to constitute a stage; he named this stage a "mutation," a term now used in palæontology in a sense directly opposite to its borrowed use in botany and zoology. Following the establishment of the principle of continuity by many invertebrate palæontologists came the vertebrate studies of Déperet and especially of Osborn, who in his monograph of researches on the evolution of the titanotheres ${ }^{4}$ has firmly established this principle. Every bio-mechanical organ in every part invariably arises and evolves through a continuous process, and in this respect evolution is a forecast of ontogeny or individual development. Each new adaptive organ rises gradually and continuously out of the germplasm, passes into a stage of mechanical perfection, and then subsides into the germ-plasm and disappears.

IV. The principle of germinal or evolutionary trend in a definite direction. So far as I know, this was first expressed by the Austrian palæontologist Neumayr, who applied to this trend the term "Mutations richtung," equivalent to "trend of evolution." He applied

\footnotetext{
1 Continued from p. 926.
"See D'Arcy W. Thompson, "Growth and Form" (Cambridge, 1917), Chapter $x$. See Osborn, "Origin and Evolution of Life" (New York, 1916), Introduction.

- H. F. Osborn, "The Titanotheres of Ancient Wyoming, Dakota, and Nebraska," United States Geological Survey Monograph, No. 55. Now in press. A sequel to the monographs of O. C. Marsh.
}

NO. 2903 , VOL. I I 5$]$ it to just such characters of ornament, shell marking, and shell proportion as those observed by his predecessor Waagen in his "mutations." This cumulative orthogenetic trend in evolution of organs in certain definite directions is also firmly established in both invertebrate and vertebrate palæontology. It may be quite antecedent to ontogenetic habit or function and, consequently, by its independence of origin is purely germinal; it is a process resident in the heredity germ itself.

V. The principle of accelevation and retardation. Observed by Von Baer in embryology, this principle was formulated and elaborated in palæontology by Alpheus Hyatt, a member of this Academy. It is one of the most important principles in bio-mechanical evolution, as hurrying forward or holding back the development of organs to the exact moment when they are first needed and most needed by the organism. For example, in all hoofed animals of the plains, where the young may be required to run with the mother immediately after birth, the adult limb proportions are pressed back into the prenatal stage so that the young at birth may be able to keep pace with the mother, for a few moments at least. This biomechanical principle can only be explained by Darwin's selection principle operating on heritable variations.

VI. The principle of allometry, or change of proportion as studied by Osborn in the Titanothere Monograph." Adaptation through change of proportion is the most universal principle in vertebrate evolution. It is due to three causes : $(a)$ the elongated neck of the giraffe, alternately cited by Lamarck and Darwin as due to inheritance or selection, may be experimentally shown to be due to the deferred inheritance of an acquired adaptation through the coincident selection of all fluctuations in the adaptive direction. (b) All changes of proportion which are not caused by either habit or selection fall under the principle of "Mutations richtung" or evolutionary trend, whether observed in the shells of invertebrates or in the head form of the mammals, including man. (c) All changes of proportion which are influenced by habit are due to this dual mode of accumulation; by experimental adaptation in a single lifetime, e.g. the hind limbs of a dog with proportions of the running type are changed into hind limbs with proportions of the leaping type by the process brought about by the principles of compensation and self-adaptation.

VII. The principle of rectigradation ${ }^{5}$ in adaptive organs arising from the germ-plasm passing continuously from the most rudimentary into the most efficient and highly developed stages. First observed in the Primates in 1889 by Osborn, this principle has since been confirmed in the other four great orders of mammals, the horses, rhinoceroses, titanotheres, and the proboscideans (Osborn, I889-I9II). Consequent on this principle is the "potential homology" of organs (Osborn, I9O2-rgII), in contrast with the true homology of Aristotle, or " genetic homogeny." For example, all the bony elements of the limb of the Tetrapoda are homologous in Aristotle's sense; all except one of the elements in the grinding teeth of the mammals are instances of potential homology rather than of genetic.

${ }^{5}$ Eimer sets forth a graduated evolution as comparable to organic growth. The conception of rectigradation as defined by Osborn is not found in Eimer's volume, nor is the word "orthogenesis" attributed to Eimer of the same import as rectigradation. (Eimer-Cunningham, "Organic Evolution as the Result of Acquired Characters," I 890.) 
VIII. The principle of experimental adaptation. This principle is fundamental ; the "trial and error " or experimental impulse as observed in the freely moving Protozoa prevails throughout the animal kingdom and is one of the chief ontogenetic phenomena. Thus many of the higher mammals, especially the equines and the proboscideans, guide their own evolution through initiative and resourcefulness just as man is able to guide his own evolution in adaptation to new conditions of environment and biota. This principle in part accounts for the extraordinary diversity of the mammalian kingdom, which since the close of the Cretaceous has radiated from small ratlike forms into the marvellous diversity of the existing mammalian life, while the Crocodilia and Testudinata remain as they were at the close of the Age of Reptiles.

IX. The principle of adaptive radiation, continental, local, oceanic. While all sessile organisms like plants and sessile invertebrates develop superb bio-mechanisms simply in direct reaction to stresses and strains, and while static organisms like the Crocodilia and Testudinata remain in the condition of arrested development through conservation of habit, the freely mobile organisms like the Lacertilia and Ophidia among reptiles, the birds, and all divisions of the mammals enter new ontogenetic and phylogenetic phases through the principle of adaptive radiation (Osborn), which is an elaboration of Lamarck's ebranchement and Darwin's "divergence." Repeatedly in all four classes of vertebrates we observe the cycle of terrestrial, fossorial, aquatic, often ending in marine adaptation of the body and limbs. Also terrestrial, arboreal, glissant, and volant forms arise. Meanwhile insectivorous diet may branch into carnivorous or omnivorous on one hand, or into herbivorous or frugivorous, leaf-eating, browsing, grazing adaptations of the general mechanism on the other. Under this principle as developed by Osborn fall the bio-mechanical processes of convergence, the homoplasy of Lankester, and the alternative habitat discussed and elaborated by Dollo. In every instance where we can observe transition from one habitat or from one feeding to another, the adaptive response of the organism to the new conditions is immediate. The response of heredity to new conditions is very gradual. For example, heredity may conserve "palæotelic" adaptations in a " cœnotelic" exterior. In Gregory's language, "heritage" is long concealed by "habitus," but after the passage of very long periods of time cœnotely replaces palæotely and habitus gives rise to new heritage.

It should be said that, of these nine bio-mechanical principles, five were first observed in zoology and were afterwards confirmed and greatly clarified in palæontology, namely, the principle of function preceding form, the compensation principle of Aristotle and St. Hilaire, the acceleration and retardation principle, the experimental adaptation principle, and the adaptive radiation principle. Four may be observed only in palæontology, namely, the mutation principle of Waagen and the "Mutations richtung" of Neumayr, the rectigradation principle of Osborn, the continuity principle of Waagen, Neumayr, and Osborn.

These nine principles are well-substantiated facts ; they are not hypotheses or theories. They include the observed modes by which new mutations, new species, new genera, new families, new orders of vertebrates arise in their bio-mechanical evolution. Every particulate organ of the skull, limbs, and teeth develops and evolves continuously in perfect biomechanical response or reaction to fixed or changing life environment and habit. The germ-plasm conditioning this bio-mechanical adaptation also evolves continuously, but lags far behind ontogenic adaptation, whether it be to produce the static mechanism of
Sequoia gigantea or the mobile mechanism of the sperm whale, Physeter macrocephalus, or the no less marvellous mammoth, Elephas primigenius. Slowly following in secular time, adaptive reactions to new living environment, to new forms of self-adaptation, there is the onward germinal impulse. The rise of new rectigradations and allometrons in the germ-plasm is not in the nature of vitalism or preformation, but of more or less deferred adaptive reaction to secular experience.

Passing from the boundaries of actual observation, we may point out the bearing of the above nine principles upon some of the current hypotheses and opinions as to the causes of evolution.

It is, for example, frequently stated that environment is the cause of evolution; this is only a quarter truth, as may be seen by consideration of the following eleven observations made in palæontology :

x. Bio-mechanical evolution may be as rapid in a fixed physical environment like the ocean as in a changing environment like a continental surface, because bio-mechanical evolution depends as much on living environment (biota), on self-adaptation, on plastic heredity as it does upon physical environment.

2. As to static heredity, during the whole changing period of the Age of Mammals, mechanical evolution of two orders of reptiles, the Crocodilia and the Chelonia, was practically arrested, while mechanical evolution of the mammals was extremely rapid. This principle shows that certain animals had a fixed heredity while others had a plastic heredity.

3. As against Lamarckism and the Lamarckian hypothesis of the influence of animal intelligence on evolution, mechanical adaptation of the small-brained, cold-blooded reptiles was as great, or greater, during the Age of Reptiles as that of the warm-blooded, large-brained mammals during the Age of Mammals.

4. As against Lamarckism which involves the efforts, desires, and movements of animals in mechanical evolution, it may be said that mechanical adaptations in nerveless plants which have no movements or nervous systems are quite as remarkable as are those in the nervous and sensitive and mobile vertebrates. This proves that mechanical adaptation may be quite independent of the nervous system of animals or of the inherited effects of reaction to motion. Nevertheless, as Lamarck believed, all mobile vertebrates, like all human beings, are able to alter the trend of their evolution through the search of new food (biota), through meeting new competitors (biota), through entering new environment by geologic change or by migration (environment), through self-adaptation by new habits (ontogeny).

5. As against Lamarckism, in the horse family it is observed that mechanical evolution of the limbs and feet, which are rapidly improved and adapted by habit (ontogeny), is less rapid and less remarkable than the mechanical evolution of the teeth, organs which are entirely preformed by heredity and are destroyed by use and habit in ontogeny. The same is true of the marvellous mechanical evolution of the grinding teeth of the Proboscidea.

6. As against Darwin's principle of bio-mechanical evolution through selection and the survival of favourable variations, we observe that the mechanical evolution of the most rapidly breeding animals, such as the rodents, was much less extreme during the Pleistocene time than the mechanical evolution of the slowest breeding animals, the elephants. During the 500,000 years of the Pleistocene period there was an intensely rapid evolution of the dental mechanism of the slow-breeding elephant and little or no evolution in the dental evolution of the fast-breeding rodents.

7. As against both Lamarck and Darwin, the prin ciple of rectigradation (Osborn) shows that new

NO. 2903 , VOL. I I 5 ] 
mechanical adaptation organs arise out of the germplasm without the antecedent action of self-adaptation. (a) While in all parts of the skeleton the principle of mechanical self-adaptation prevails and new proportions, new characters, new adaptations, new functions, new modes of locomotion may be created in the lifetime of a single individual, all that is transmissible in heredity is the germinal variation to plasticity or adaptability in the desired direction, which may be accumulated through coincident selection as applied by Osborn, Baldwin, and Morgan. (b) Even more perfect mechanical adaptations arise in the grinding teeth which are not perfected during lifetime.

8. As against mutational or saltatory hypotheses of evolution hitherto held by Bateson and his school, the principle of bio-mechanical continuity is so firmly established that we may attribute all discontinuity in bio-mechanical evolution to abnormal, unnatural, pathogenic causes or, through recent discovery, to endocrinal disturbance. Whatever may be true in bio-chemical evolution, in colour, in immunity, in metabolism and phenomena of that order, we may be certain that the bio-mechanical evolution of the skeleton and teeth as observed in palæontology assumes and follows its firm and undeviating order.

9. Bio-mechanical evolution as observed in full palaontological series, whether vertebrate or invertebrate, gives the death-blow to the chance hypothesis of Democritus and Empedocles raised into a scientific system in the subsidiary fortuitous selection hypothesis of Darwin. Nature is observed to take nochances, either in the transformation of existing mechanical organs or in the origin of new mechanical characters and inventions. New parts of the organic machine arise in rudimentary condition but perfect order out of the germ-plasm when the demand for them arises; they do not arise automatically without an antecedent bio-mechanical stimulus. They play their continuously adaptive service; when no longer useful they subside and sink back into the germ-plasm, where the power of reproduction is ultimately lost.

Every single one of hundreds of bio-mechanical characters of which the evolution has been observed follows the nine principles enunciated above.

Io. The loss of bio-mechanical organs in the vertebrates is never sudden, as if due to the presence and absence principle of Mendelism. Organs evolved through a long process of continuity show remarkable heritable stability, like longheadedness in man or in the hoofed mammals when crossed with broadheaded types. In the horse-ass hybrid, for example, most of the bio-mechanical skeletal characters transmitted are those of the horse, all of which have evolved over a very long period of time-hundreds of thousands of years. Certain of the bio-mechanical characters and most of the psychic characters are those of the ass. Thus a continuity in bio-mechanical evolution may give rise to Mendelian discontinuity in hybridising, exactly as it does in the matter of bio-chemical evolution.
I I. Every race will move or less rapidly lose its typical form in any one of four ways consistent with the tetraplastic and tetrakinetic principle of Osborn : (a) by alteration of its internal energies of heredity (phylogeny) ; (b) by alteration of the external energies of environment; (c) by alteration of the external energies of the biota of plant and animal environment; (d) by alteration of the internal energies of habit or ontogeny. Any one of these four energetic changes will immediately precipitate a new action of selection, and as a secular process will alter the germ-plasm.

It appears from these eleven observations that palæontology is a two-edged sword which is equally ruthless in the Darwin-Weismann and the Lamarckian fields of speculation.

In conclusion, what really happens in the natural origin of species in bio-mechanical characters is this: Whenever all the four energetic conditions of heredity, of environment, of biota, of habit or ontogeny, and the non-energetic condition of the struggle for existence (selection) are the same, there will arise similar ascending mutations, species, genera, families. New similar or parallel species of hoofed animals actually arise at approximately, if not at precisely, the same rate, whether we observe them in France, Mongolia, or the Rocky Mountain region.

My rejoinder to Bateson's statement " that "the origin and nature of species remains utterly mysterious" is that thirty-six years of intensive palæontologic exploration and research have so clearly and repeatedly revealed how new bio-mechanical species arise that we can safely predict not only what the species is, but also where it is most likely to be found and in what stage of evolution it will be found. Such prediction has recently been fulfilled in a most brilliant manner in our discoveries of the Titanotheres in central Mongolia. Whatever may prove true as regards species founded on bio-physical or bio-chemical characters, the research is nearly closed on the modes of origin of bio-mechanical species, because we have little more to learn.

The causes of these origins is quite another matter. Some day we may be able to work out the separate contribution of each of the four energetic factors, heredity, environment, ontogeny, biota to germinal evolution. We palæontologists observe exactly how the process of germinal evolution of bio-mechanical characters goes on, adaptive in every stage, just as the embryologists observe how the process of adaptive development goes on whereby the invisible germ turns gradually into the adult and perfected skeleton and teeth. There is no accident in either mode of transformation, evolutionary or developmental, nor is there anything that we can comprehend. On the whole, the order of evolution imitates the order of development; both processes, to our mind, are equally inexplicable, and will probably remain so.

- William Bateson's observations on discontinuity in the origin of species first appeared in his "Materials for the Study of Variation," I894. More recent are his British Association address in Australia and his address at the Toronto meeting of the American Association quoted from above.

\section{Accuracy of Weighing in the Eighth Century.}

TWO recent papers in the Numismatic Chronicle ${ }^{1}$ contain interesting information on the remarkable accuracy of ancient weighing. Dr. G. F. Hill mentions that in a hoard of 20 gold staters of Lysimachus (c. 355-28I B.c.), in mint state, the extreme weights were 8.62 and 8.42 grams, i.e. the maximum variation was 2.3 per cent. Eleven of the coins, however, had weights with a much smaller range, namely, 8.57 to $8.5^{2}$ grams, a variation of only $0.5^{8}$ per

${ }^{1}$ G. F. Hill, "The Frequency Table," Fifth Series, vol. 4, p. 76, 1924; W. M. F. Petrie, "Glass Weights," Fourth Series, vol. I8, p. II I, I918. cent. Dr. Hill considers this degree of accuracy to be no greater than might be obtained by cutting a bar of uniform thickness into equal lengths with an ordinary measure. The smallest weight about which the Greeks cared seems to have been not less than 0.05 gram

Much greater accuracy is shown in certain Arabian glass coin-weights of the eighth century which are described by Sir Flinders Petrie. The average error of dinar and dirham weights of this century is 0.004 gram; in the early weights the accuracy is 